\title{
IDENTIFYING LONG-TAILED WEASELS ON THE PRAIRIES
}

RICK F. COURTNEY and NANCY J. SMITH, \#5 7812 Hunterview Drive NW, Calgary, Alberta. T2K 5C9

The Prairie Long-tailed Weasel (Mustela frenata longicauda) has been listed as threatened by the Committee on the Status of Endangered Wildlife in Canada (COSEWIC) since 6 April 1982. Concern was expressed about a possible decline in this subspecies as early as $1977 .{ }^{4}$ Despite this relatively longstanding concern, little is known about this weasel outside of Manitoba.

Table 1 presents a method by which naturalists can contribute to knowledge of the status of this weasel in the prairies. The observations in Table 1 were collected by the authors in a one month period in the Calgary area, largely as incidental observations. The majority of the observations were road kills. Although unfortunate, road kills can provide useful information on distribution, measurements, field marks, etc. for elusive species like the Long-tailed Weasel. The possibility of measuring and sexing individuals depends upon the condition of the carcass.

The summer coloration (late April to mid-October) of Prairie Long-tailed Weasels differs from the Long-tailed Weasel depicted in the Peterson's series field guide to the mammals. ${ }^{3}$ The white line down the hind leg which is supposed to distinguish the Long-tailed Weasel from the Ermine is very difficult, if not impossible, to see on a free-ranging animal.

Compared to the Peterson's field guide, the Prairie Long-tailed Weasel is a much lighter brown on the dorsal surface and yellowish to buff-colored on the underside. This summer coat description for the Prairie Long-tailed Weasel seems to hold
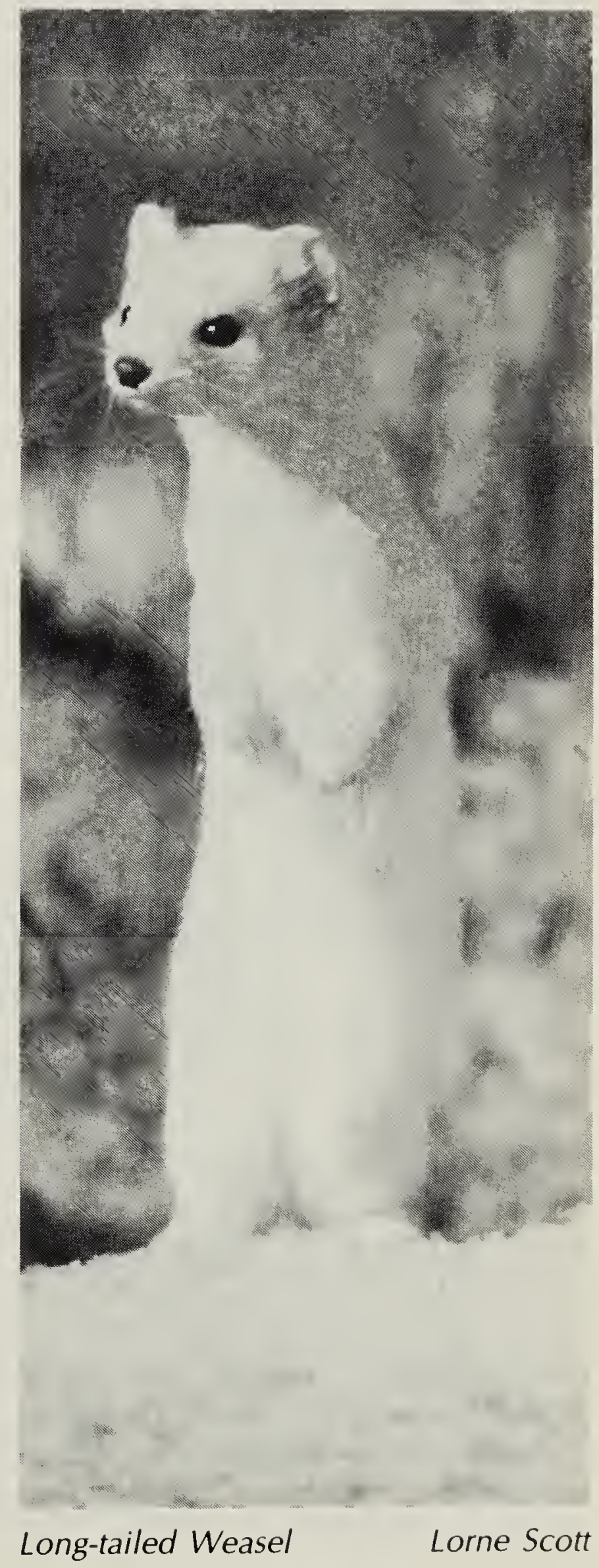


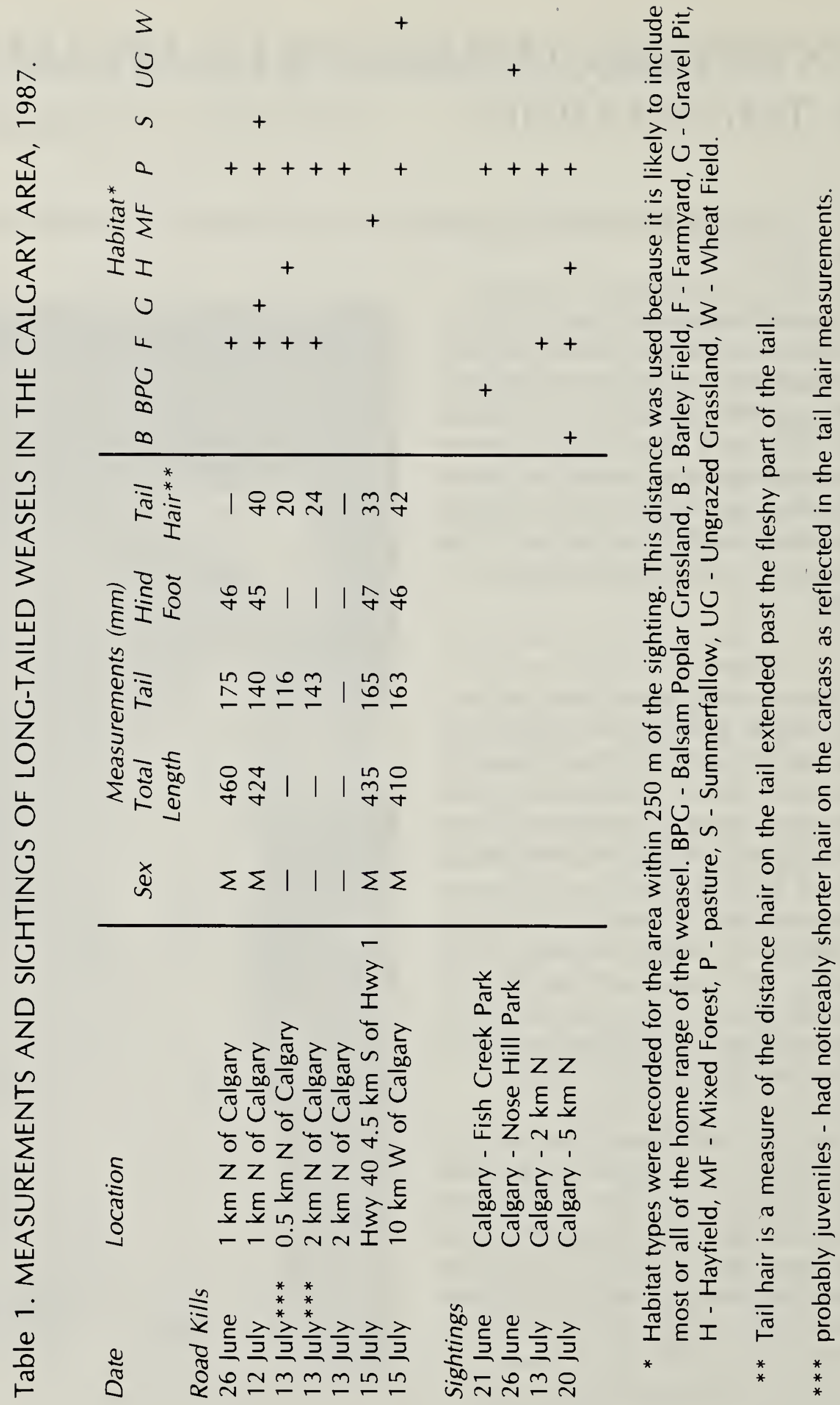

in southwestern Alberta (this study), Ermine is characterized as being white on Saskatchewan and North Dakota. ${ }^{25}$ the underside although Soper described However, Soper describes the Prairie Ermine as sometimes having pale yellow Long-tailed Weasel as "white below, underparts. ${ }^{2} 56$ Therefore, weasels with sometimes tinged with pale yellow." 6 The yellowish to buff-colored undersides are 
probably Long-tailed Weasels; weasels with pale yellow or white undersides could be either Long-tailed Weasels or Ermine; even familiarity with the weasels of the locality does not guarantee positive differentiation on the basis of color alone. Of course the Least Weasel is easily distinguished from the other two Canadian weasel species by not having a blacktipped tail.

During moult, the belly of the Longtailed Weasel is the first part of the pelage to turn white in the fall (Oct.- Nov.) and the last to change to the summer coat in spring (April). ${ }^{5}{ }^{6}$ As a result, belly color is not a good way to distinguish the two species from October to April.

Overall size can be used to distinguish Long-tailed Weasels from Ermine in the field, but as most observers of wildlife will realize, the size of free-ranging animals is difficult to determine with any accuracy. Unfortunately these two weasel species overlap in size and accuracy is necessary to differentiate them on this basis: Longtailed Weasels range from $300-480 \mathrm{~mm}$ or more and Ermine range from 200-340 $\mathrm{mm}$ in total length. ${ }^{1567}$

Some authors have recommended a relationship between tail length and body length to separate the two species in the field. However this relationship varies greatly depending on the authority: the Long-tailed Weasel has a tail measuring
$40-70 \%$ of its body length while the Ermine has a tail measuring $30-50 \%$ of its body length. ${ }^{56}{ }^{7}$ Obviously there is some overlap, but a rule of thumb would be: a weasel with a tail length greater than half the body length is a Long-tailed Weasel; a tail length less than half the body length is probably, but not always, an Ermine.

A more accurate method of identifying to species prairie weasels in all seasons and localities is by measurement. That requires having the specimen "in hand," which is where road kills and other methods of obtaining carcasses are valuable. A simple measure of the tail length (excluding hair) clearly separates adult Prairie Long-tailed Weasels from Ermine. The Long-tailed Weasel is larger than the Ermine but, as in all weasels, females are smaller than males of the same

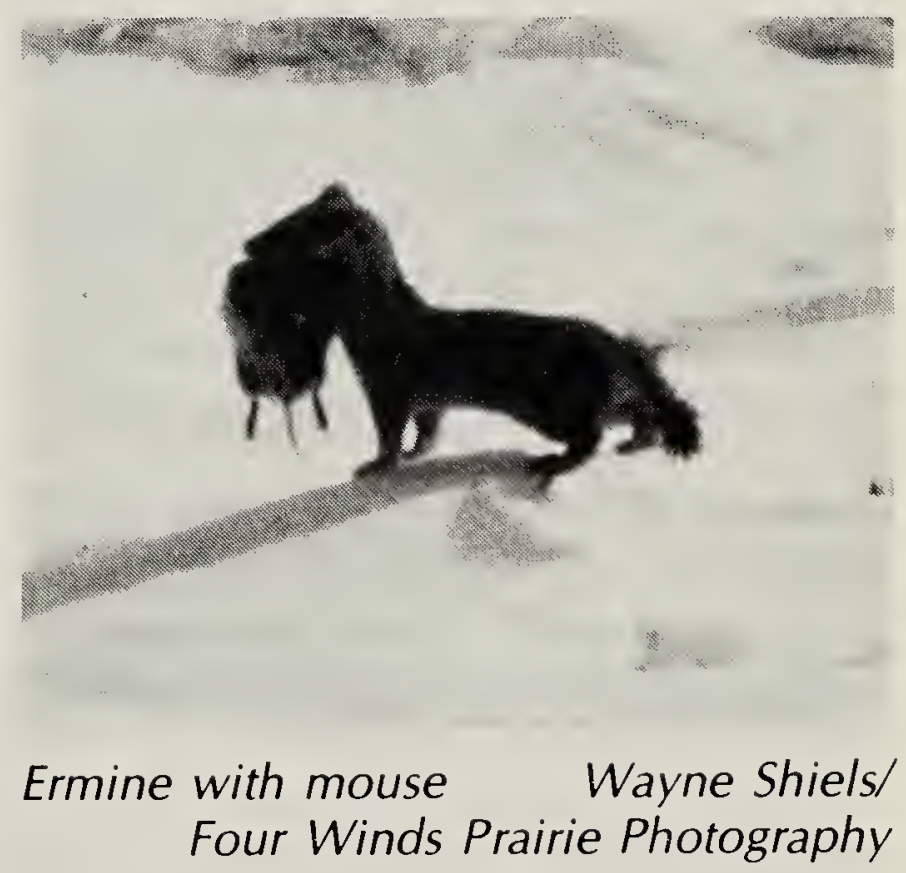

Table 2. PUBLISHED RANGES FOR ADULT TAIL LENGTHS OF MALE ERMINE AND FEMALE PRAIRIE LONG-TAILED WEASELS

$\begin{array}{ll}\text { Source } & \text { Location } \\ \text { Beck }^{2}{ }^{*} & \text { Saskatchewan } \\ \text { Soper }^{6} & \text { Alberta } \\ \text { Banfield }^{1} & \text { Canada } \\ \text { Jones et al. }{ }^{5} & \text { Nebraska }\end{array}$

Tail Length Range ( $\mathrm{mm}$ )

$\begin{array}{cc}\text { Female Long-tailed } & \text { Male Ermine } \\ 139-170 & 60-100 \\ 138-139 & 81-88 \\ * * & 65-90 \\ 115-142 & 70-101\end{array}$

* Beck's figures are for both sexes combined

** Banfield's figures are for a smaller eastern subspecies and are not applicable to Prairie Longtailed Weasels. 
species. The area of likely confusion concerns male Ermine and female Long-tailed Weasels which are closest in size. Table 2 presents published information on adult tail length for female Prairie Long-tailed Weasels and compares it to published male Ermine measurements.

There is no overlap between adults of the two species and any weasel with a tail length over $100 \mathrm{~mm}$ is likely to be an adult or juvenile Long-tailed Weasel. The tail is used for this comparison because it is the commonly measured body part that is most likely to remain intact for measurement. This method of identification should only be used in the prairies as other subspecies of Long-tailed Weasel may be smaller and overlap Ermine in tail length.

Juvenile Long-tailed Weasels, which may have shorter tail lengths, can be distinguished from adults by their shorter tail hair (as measured in Table 1). Since young begin to forage with the female as early as 6 or 7 weeks after birth and reach adult size in 10 to 11 weeks, confusion could only occur for a short period during summer. ${ }^{5}$

Identifying weasels accurately in the field is not always possible based on any single characteristic. Some individuals are clearly one species or the other but other individuals require careful consideration of size, coloration and tail length in comparison to body length. However with repeated observaitons and access to "in hand" specimens, observers can quickly become proficient at identifying these two species accurately.

The Wild West program was launched in 1986 by the World Wildlife Fund, Canada, to aid in the conservation of endangered prairie habitats and species. As part of this program, an evaluation of the status of the threatened Prairie Long-tailed Weasel has begun. You can help determine the status of the Long-tailed Weasel in the prairie provinces by sending Wild West any information you may have. If possible, include the date, location, description of field marks, measurements, sex, habitat within $250 \mathrm{~m}$ and if dead, the cause of mortality (eg. road-kill, dog, unknown). All sightings consisting of the species, approximate date and location are valuable. If the Long-tailed Weasel seems rare or absent in your area or seems to be increasing or decreasing in abundance, it is important to report this information as well. For further information contact:

Prairie Long-tailed Weasel Study c/o Wild West Program

World Wildlife Fund Canada \#204 - 1422 Kensington Road NW Calgary, Alberta

T2N $3 P 9$

\section{Acknowledgement}

We would like to thank Miles ScottBrown for his advice in preparing this paper.

1 BANFIELD, A.W.F. 1981. The mammals of Canada. Univ.of Toronto Press, Toronto. 438 pp.

2 BECK, W.H. 1958. Guide to Saskatchewan mammals. Sask. Nat. History Soc. Publ. No. 1. $52 \mathrm{pp}$.

3 BURT, W.H. and R.P. GROSSENHEIDER 1976. A field guide to the mammals. Houghton Mifflin Co., Boston. 289 pp.

${ }^{4}$ GOVERNMENT OF CANADA 1977. Report on the status of Canadian wildlife used by the fur industry. Revised Edition. 66 pp.

5 JONES, J.K., Jr., D.M. ARMSTRONG, R.S. HOFFMANN and C. JONES 1983. mammals of the Northern Great Plains. Univ. Nebraska Press. $379 \mathrm{pp}$.

6 SOPER, J.D. 1964. The mammals of Alberta. Hamley Press Ltd., Edmonton 402 pp.

7 SVENDSON, G.E. 1982. Weasels. IN J.A. CHAPMAN and G.A. FELDHAMER, Eds. Wild Mammals of North America. Hopkins Univ. Press, Baltimore. 1147 pp. 